\title{
Adjuvant Growth Hormone for Ovulation Induction with Gonadotropins in the Treatment of a Woman with Hypopituitarism
}

\author{
Ariadne Daniel, ${ }^{1}$ Shereen Ezzat, ${ }^{2}$ and Ellen Greenblatt ${ }^{1}$ \\ ${ }^{1}$ Department of Reproductive Endocrinology and Infertility, Mount Sinai Center for Fertility and Reproductive Health, \\ 250 Dundas Street West, Suite 700, Toronto, ON, Canada M5T $2 Z 5$ \\ ${ }^{2}$ Division of Endocrine Oncology, University Health Network, 585 University Avenue, Toronto, ON, Canada M5N 2N2
}

Correspondence should be addressed to Ellen Greenblatt, egreenblatt@mtsinai.on.ca

Received 2 May 2012; Accepted 26 June 2012

Academic Editors: G. Aimaretti, J. P. Frindik, and A. J. O’Sullivan

Copyright () 2012 Ariadne Daniel et al. This is an open access article distributed under the Creative Commons Attribution License, which permits unrestricted use, distribution, and reproduction in any medium, provided the original work is properly cited.

\begin{abstract}
Objective. To report the prestimulation use of adjuvant $\mathrm{GH}$ for gonadotropin ovulation induction in a woman with hypopituitarism and GH deficiency who previously failed to respond. Design, Patients, and Measurements. A 31-year-old nulliparous woman presented with hypopituitarism and GH deficiency after failing ovulation induction with high dose gonadotropins. A trial of GH was undertaken for 5 months prior to ovulation induction resulting in normalization of IGF-I levels. Results. Women with hypopituitarism are known to have lower pregnancy rates after ovulation induction with need for higher doses of gonadotropins. A small subset of these patients do not ovulate. This patient had successful ovulation induction and pregnancy with prestimulation GH. Conclusions. This case suggests that the use of adjuvant GH in a GH-deficient patient several months before the use of human menopausal gonadotropin results in ovulation and pregnancy.
\end{abstract}

\section{Introduction}

There is a growing body of literature which suggests that the addition of GH to gonadotropins improves ovarian stimulation and pregnancy rates in poor responders undergoing ovulation induction, and controlled ovarian stimulation for in vitro fertilization [1-3]. Women with hypopituitarism are known to have lower pregnancy rates after ovulation induction with need for higher doses of gonadotropins than with other causes of anovulation [4, 5]. A subset of these women do not respond despite high doses of gonadotropins. In these women, if GH deficiency is discovered, supplementation with GH has been shown to improve chances of ovulation and pregnancy in a few case studies [6]. We report the case of a nulliparous woman with hypopituitarism and GH deficiency who achieved a viable pregnancy with $\mathrm{GH}$ priming prior to ovulation induction with hMG after failing high dose hMG alone.

\section{Case Report}

A 31-year-old Caucasian woman was referred with a history of primary infertility. In 1994, she underwent a transsphenoidal right hemihypophysectomy with a diagnosis of corticotroph tumour. Following surgery, she developed hypopituitarism and secondary amenorrhea. She underwent insulin tolerance testing confirming a GH deficiency and that her cortisol responses had returned to normal. Medical history included class III obesity (BMI $40.3 \mathrm{~kg} / \mathrm{m}^{2}$ ), bipolar disorder, and asthma. Her 33-year-old male partner had a normal semen analysis.

She had previously been to another clinic and underwent two cycles of hMG containing a $1: 1$ ratio of urinary FSH : LH, 75 IU of each. The first cycle used a total of $1500 \mathrm{IU}$ and the second cycle used $3750 \mathrm{IU}$, neither of which resulted in the development of a dominant follicle. A final attempt with hMG was performed in our clinic using a step-up protocol as follows: hMG (Menopur; Ferring, Canada) at 
150 IU daily was started on day 3 of an induced menstrual cycle. After 5 days of stimulation her estradiol $\left(\mathrm{E}_{2}\right)$ level was $100 \mathrm{pmol} / \mathrm{L}$ and there was no dominant follicle, thus her dose was increased to 225 IU daily. Her dose was increased again 3 days later to 300 IU daily as there was no change in her hormone profile or ultrasound. By day 21 of stimulation, she developed 4 follicles between $1.47-1.64 \mathrm{~cm}$ in diameter; however, the $\mathrm{E}_{2}$ level was only $329 \mathrm{pmol} / \mathrm{L}$. HCG (Merck, Canada) 10,000 IU was given to stimulate the LH surge and intercourse advised for three nights. Eleven days later her menses started spontaneously. A total of $4125 \mathrm{IU}$ of hMG were used in that cycle.

In light of the massive doses of gonadotropins required to induce ovulation and the low $\mathrm{E}_{2}$ per follicle, an antimullerian hormone $(\mathrm{AMH})$ was done to assess her ovarian reserve. The AMH was $37.72 \mathrm{pmol} / \mathrm{L}$, well above the average value expected for her age, demonstrating good ovarian reserve $[7,8]$.

It was hypothesized that her poor response to gonadotropins may be due to her history of GH deficiency. GH levels were not measured due to its short half-life, instead the more reliable level of IGF-I was used. Her baseline IGF-I level was below the normal range $(72 \mathrm{mcg} / \mathrm{L}$; normal $115-307 \mathrm{mcg} / \mathrm{L})$. In consultation with medical endocrinology, a trial of $\mathrm{GH}$ (Humatrope; Eli Lilly, Canada) was given for 5 months. The initial dose of Humatrope $0.30 \mathrm{mg}$ subcutaneous daily was increased to $0.50 \mathrm{mg}$ to obtain an IGF-I level in the normal range $(253 \mathrm{mcg} / \mathrm{L}$; normal $115-307 \mathrm{mcg} / \mathrm{L})$. Thyroid and adrenal function were monitored with no abnormalities.

Ovulation induction was attempted again using Menopur 375 IU daily started on day 3 of an induced menstrual cycle, and she continued with daily GH. On day 12 of stimulation, 6 follicles measured between $1.40-1.65 \mathrm{~cm}$ in diameter and due to a concern with overstimulation, her dose was decreased to Menopur 262.50 IU daily. By day 14 of stimulation, her $\mathrm{E}_{2}$ level was $1620 \mathrm{ng} / \mathrm{mL}$ and 3 follicles measured $1.40,1.85$, and $1.95 \mathrm{~cm}$ in diameter. HCG 10,000 IU was given and an intrauterine insemination performed 36 hours later.

The patient conceived and was seen at 6 weeks and 3 days for an ultrasound revealing one fetal heart rate. Humatrope was stopped at 8 weeks gestation. She has not developed impaired glucose tolerance. Her Cushing's disease remains in remission. The pregnancy is ongoing.

\section{Discussion}

Adjuvant GH has been used in women with hypogonadotropic hypogonadism and GH deficiency to reduce the amount of gonadotropins required for ovulation induction with mixed results [9-11]. There are only a few reports where adjuvant $\mathrm{GH}$ has been used in women with $\mathrm{GH}$ deficiency resulting in an increased pregnancy rate [1216]. Most papers describe heterogeneous groups of patients without testing for IGF-I and/or GH levels.

This case highlights the use of adjuvant $\mathrm{GH}$ in an adult $\mathrm{GH}$ deficient patient who had previously been resistant to high dose hMG ovulation induction. As with many patients with hypogonadotropic hypogonadism, the response to
hMG alone for this patient was poor and did not result in ovulation. This triggered the commencement of $\mathrm{GH}$ replacement with confirmation of the normalization of IGFI levels before ovulation induction. The administration of GH as "priming" before hMG resulted in ovulation and pregnancy. This is congruent with other reports which suggest the importance of prestimulation normalization of IGF-I and/or GH levels $[6,15,16]$.

With GH treatment there is a reported risk of glucose intolerance and the potential for pituitary/hypothalamic tumour recurrence and cancer. Nevertheless, there have been no reports in the few cases in the infertility literature with short term GH use [17]. Patients on GH with diabetes mellitus must be monitored carefully as changes may need to be made to their antidiabetic medications. Therefore, the use of GH in these women must continue to be investigated.

While several papers have suggested possible protocols, the most effective dose, start time, and duration of use for GH are not yet standardized in women with hypogonadotropic hypogonadism and GH deficiency. However, the evidence continues to mount for treatment of these women with $\mathrm{GH}$ and normalization of IGF-I levels before hMG stimulation for ovulation induction resulting in the highest chance of successful pregnancy.

\section{Disclosure}

This research did not receive any specific grant from any funding agency in the public, commercial, or not-for-profit sector.

\section{Authors' Contribution}

E. Greenblatt was the primary reproductive endocrinology and infertility specialist involved in this patient's care and determined the treatment protocols. She determined that the features of this case made it unique enough to write a case report. S. Ezzat was the primary endocrinologist for this patient and monitored her through the treatment with $\mathrm{GH}$. He provided the scientific information regarding $\mathrm{GH}$ supplementation in patients with panhypopituitary. Both E. Greenblatt and S. Ezzat were involved in the editing of this case report. A. Daniel collated the details of the case and wrote the paper. All authors contributed to revising the paper and approving the final version to be published.

\section{References}

[1] D. Kyrou, E. M. Kolibianakis, C. A. Venetis, E. G. Papanikolaou, J. Bontis, and B. C. Tarlatzis, "How to improve the probability of pregnancy in poor responders undergoing in vitro fertilization: a systematic review and meta-analysis," Fertility and Sterility, vol. 91, no. 3, pp. 749-766, 2009.

[2] J. M. Duffy, G. Ahmad, L. Mohiyiddeen, L. G. Nardo, and A. Watson, "Growth hormone for in vitro fertilization," Cochrane Database of Systematic Reviews, no. 1, Article ID CD000099, 2010.

[3] D. de Ziegler, I. Streuli, D. R. Meldrum, and C. Chapron, "The value of growth hormone supplements in ART for poor 
ovarian responders," Fertility and Sterility, vol. 96, no. 5, pp. 1069-1076, 2011.

[4] N. Lewit and S. Kol, "The low responder, hypogonadotropic hypogonadism female patient in IVF: do not give up!," Fertility and Sterility, vol. 74, no. 2, pp. 401-402, 2000.

[5] R. Hall, J. Manski-Nankervis, N. Goni, M. C. Davies, and G. S. Conway, "Fertility outcomes in women with hypopituitarism," Clinical Endocrinology, vol. 65, no. 1, pp. 71-74, 2006.

[6] J. K. Park, A. A. Murphy, B. L. Bordeaux, C. E. Dominguez, and D. R. Session, "Ovulation induction in a poor responder with panhypopituitarism: a case report and review of the literature," Gynecological Endocrinology, vol. 23, no. 2, pp. 8286, 2007.

[7] S. M. Nelson, M. C. Messow, A. M. Wallace, R. Fleming, and A. McConnachie, "Nomogram for the decline in serum antimullerian hormone: a population study of 9,601 infertility patients," Fertility and Sterility, vol. 95, no. 2, pp. 736-741, 2011.

[8] S. M. Nelson and A. La Marca, "The journey from the old to the new AMH assay: how to avoid getting lost in the values," Reproductive BioMedicine Online, vol. 23, no. 4, pp. 411-420, 2011.

[9] A. G. Shaker, R. Fleming, M. E. Jamieson, R. W. S. Yates, and J. R. T. Coutts, "Ovarian stimulation in an infertile patient with growth hormone-deficient Oliver-Mcfarlane syndrome," Human Reproduction, vol. 9, no. 11, pp. 1997-1998, 1994.

[10] J. A. M. de Boer, M. van der Meer, E. A. van der Veen, and J. Schoemaker, "Growth hormone $(\mathrm{GH})$ substitution in hypogonadotropic, GH-deficient women decreases the follicle-stimulating hormone threshold for monofollicular growth," Journal of Clinical Endocrinology and Metabolism, vol. 84, no. 2, pp. 590-595, 1999.

[11] European and Australian Multicenter Study, "Cotreatment with growth hormone and gonadotropin for ovulation induction in hypogonadotropic patients: a prospective, randomized, placebo-controlled, dose-response study," Fertility and Sterility, vol. 64, no. 5, pp. 917-923, 1995.

[12] Z. Blumenfeld and B. Lunenfeld, "The potentiating effect of growth hormone on follicle stimulation with human menopausal gonadotropin in a panhypopituitary patient," Fertility and Sterility, vol. 52, no. 2, pp. 328-331, 1989.

[13] R. Homburg, C. West, T. Torresani, and H. S. Jacobs, "A comparative study of single-dose growth hormone therapy as an adjuvant to gonadotrophin treatment for ovulation induction," Clinical Endocrinology, vol. 32, no. 6, pp. 781-785, 1990.

[14] C. De Geyter, M. De Geyter, M. Bals-Pratsch, E. E. Castro Nieschlag, and H. P. G. Schneider, "Recombinant growth hormone in support of ovarian stimulation with gonadotropins in a hypophysectomized patient-a case control study," Zentralblatt fur Gynakologie, vol. 117, no. 7, pp. 381-387, 1995.

[15] A. Salle, M. Klein, V. Pascal-Vigneron, B. Dousset, J. Leclere, and G. Weryha, "Successful pregnancy and birth after sequential cotreatment with growth hormone and gonadotropins in a woman with panhypopituitarism: a new treatment protocol," Fertility and Sterility, vol. 74, no. 6, pp. 1248-1250, 2000.

[16] A. Giampietro, D. Milardi, A. Bianchi et al., "The effect of treatment with growth hormone on fertility outcome in eugonadal women with growth hormone deficiency: report of four cases and review of the literature," Fertility and Sterility, vol. 91, no. 3, pp. 930.e7-930.e11, 2009.
[17] M. E. Molitch, D. R. Clemmons, S. Malozowski, G. R. Merriam, and M. L. Vance, "Evaluation and treatment of adult growth hormone deficiency: an endocrine society clinical practice guideline," Journal of Clinical Endocrinology and Metabolism, vol. 96, no. 6, pp. 1587-1609, 2011. 


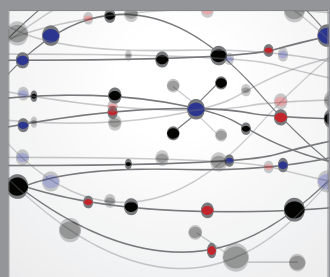

The Scientific World Journal
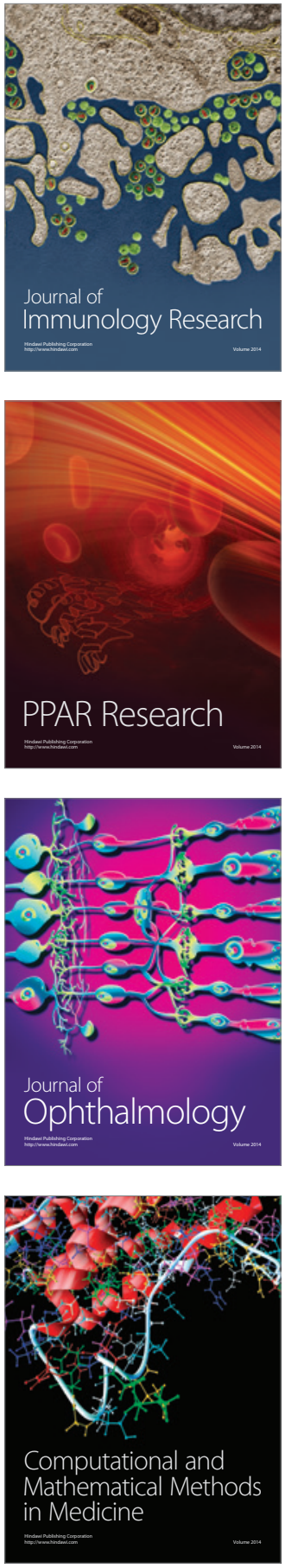

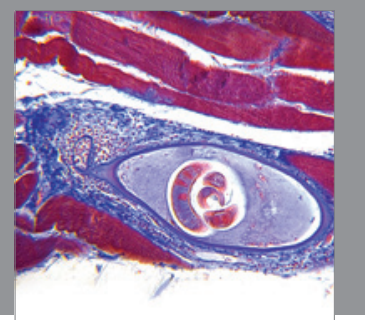

Gastroenterology

Research and Practice
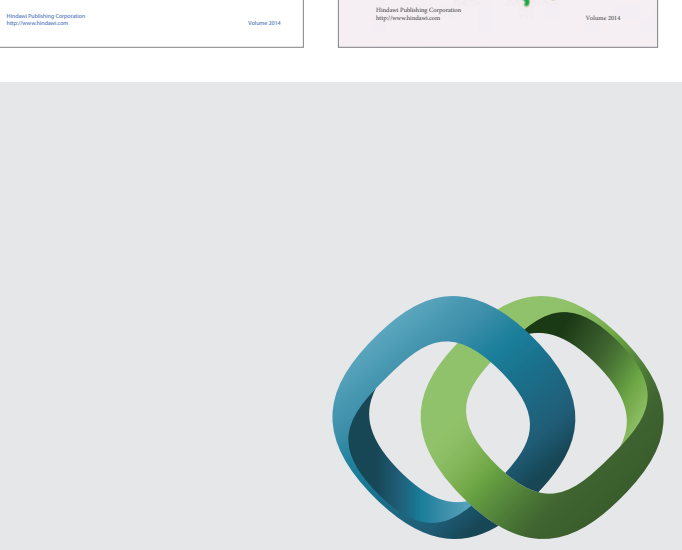

\section{Hindawi}

Submit your manuscripts at

http://www.hindawi.com
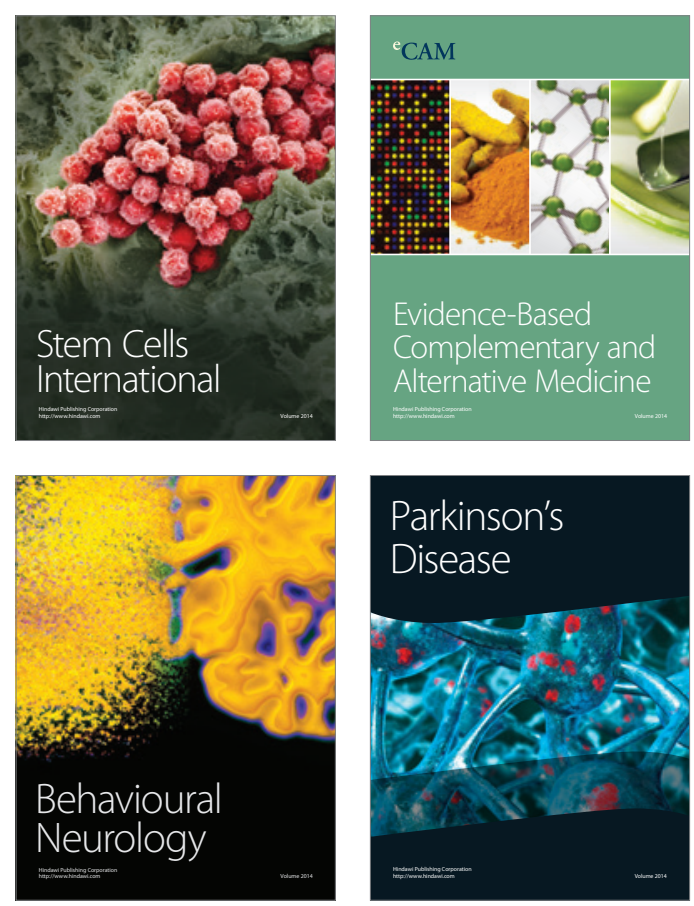

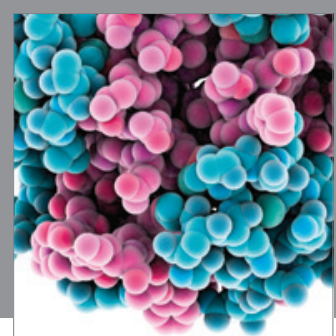

Journal of
Diabetes Research

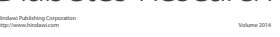

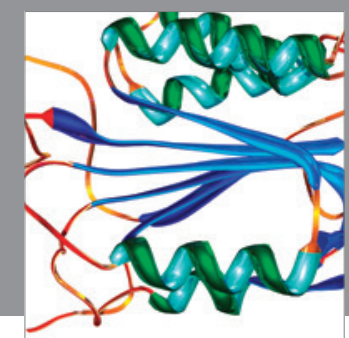

Disease Markers
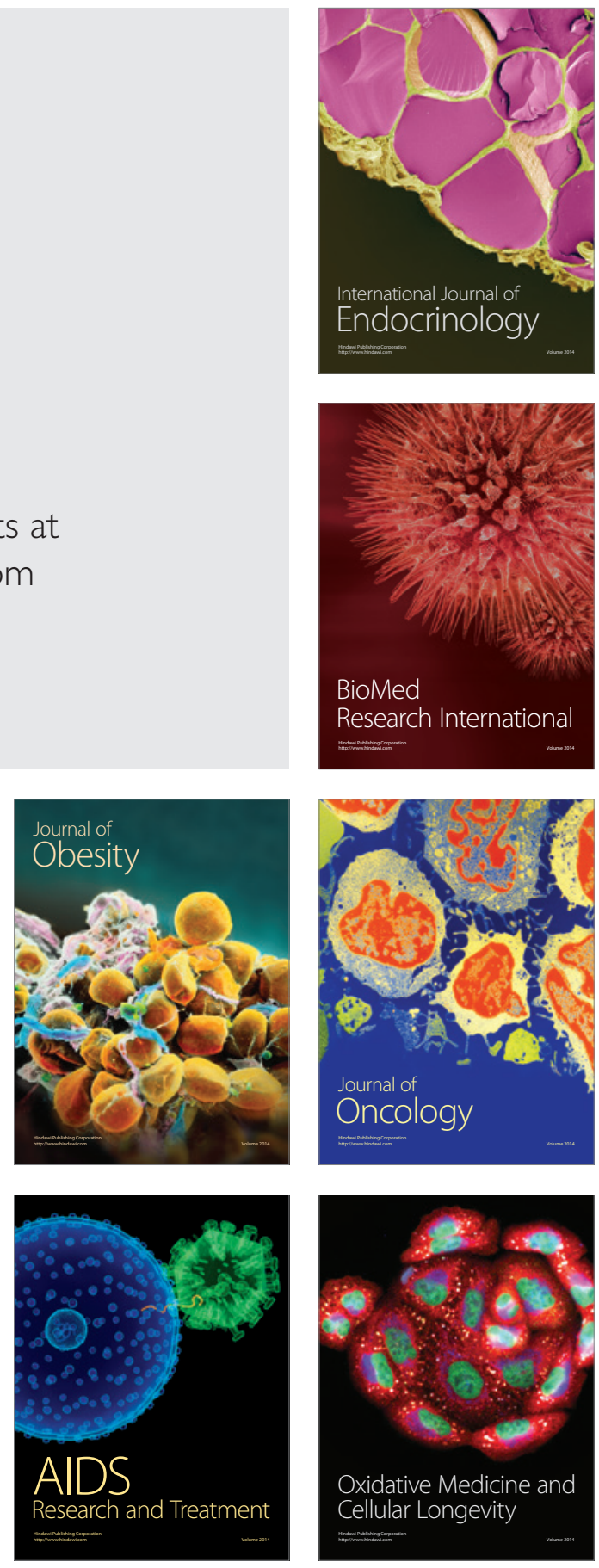